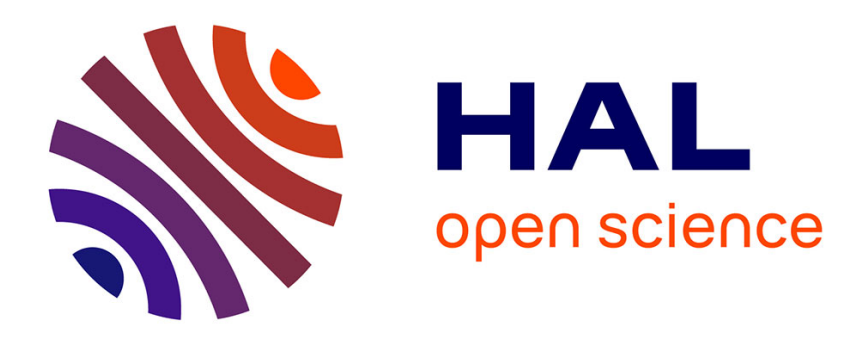

\title{
Local Structure of Ion-Bombarded $\alpha$-SiC Analyzed by EXAFS
}

\author{
M. Borowski, W. Bolse, J. Conrad
}

\section{To cite this version:}

M. Borowski, W. Bolse, J. Conrad. Local Structure of Ion-Bombarded $\alpha$-SiC Analyzed by EXAFS. Journal de Physique IV Proceedings, 1997, 7 (C2), pp.C2-711-C2-712. 10.1051/jp4:1997215 . jpa00255212

\section{HAL Id: jpa-00255212 https://hal.science/jpa-00255212}

Submitted on 1 Jan 1997

HAL is a multi-disciplinary open access archive for the deposit and dissemination of scientific research documents, whether they are published or not. The documents may come from teaching and research institutions in France or abroad, or from public or private research centers.
L'archive ouverte pluridisciplinaire HAL, est destinée au dépôt et à la diffusion de documents scientifiques de niveau recherche, publiés ou non, émanant des établissements d'enseignement et de recherche français ou étrangers, des laboratoires publics ou privés. 


\title{
Local Structure of Ion-Bombarded $\alpha$-SiC Analyzed by EXAFS
}

\author{
M. Borowski, W. Bolse* and J. Conrad* \\ LURE, bâtiment 209a, 91405 Orsay cedex, France \\ * II. Physikalisches Institut und SFB 345, Universität Göttingen, 37073 Göttingen, Germany
}

\begin{abstract}
X-ray absorption spectroscopy on the $\mathrm{Si}$ k-edge was performed on $\alpha$-SiC (6H) to monitor the evolution of the local structure around the Si atoms after ion bombardment. The samples were irradiated by $50 \mathrm{keV} \mathrm{N}_{a}$ ions at fluences of $10^{13}-10^{16}$ ions $/ \mathrm{cm}^{2}$ at a temperature of $80 \mathrm{~K}$. EXAFS analysis clearly reveals that the hetero-atomic short range order of the crystalline matrix is almost completely conserved over the crystalline-to-amorphous transition as indicated by RBS-C. Further irradiation at higher fluences results in a change of the atomic coordination and formation of homonuclear $\mathrm{Si}-\mathrm{Si}$ bonds.
\end{abstract}

\section{INTRODUCTION}

$\alpha-\mathrm{SiC}$ is a very promising semiconductor materials for electronic high speed and high temperature devices [1] with a hexagonal lattice structure formed by $\mathrm{sp}^{3}$-bonded $\mathrm{Si}_{-} \mathrm{C}_{4}$ and $\mathrm{C}_{-} \mathrm{Si}_{4}$ tetrahedrons, respectively. Ion implantation is a dedicated technique for electrical doping of the ceramic. However, SiC is easily amorphized upon irradiation at damage levels as low as $0.1 \mathrm{dpa}$ (displacements per atom) [2], which may strongly alter the electronic properties of the ceramic. Rutherford-Backscattering Spectroscopy studies in channeling geometry (RBS-C) [3] recently suggested that point defects are first accumulated in the still crystalline matrix until a critical damage level is reached. For a fluence of around $\Phi=3 \cdot 10^{14}$ at $/ \mathrm{cm}^{2}$, the crystalline-to-amorphous transition takes place. The lattice can then be described as a random network of $\mathrm{Si}_{-} \mathrm{C}_{4}$ and $\mathrm{C}-\mathrm{Si}_{4}$ tetrahedrons. Further implantation (in the order of $\Phi=10^{15}-10^{16}$ at $/ \mathrm{cm}^{2}$ ) transform this metastable amorphous phase in a atomically amorphous state [4]. Raman scattering measurements suggest the formation of $\mathrm{Si}-\mathrm{Si}$ and $\mathrm{C}-\mathrm{C}$-bonds. $A b$ initio molecular-dynamics (MD) simulation [5] have also predicted chemical short range order in amorphous $\mathrm{SiC}$, with homonuclear bonds. We therefore have performed XAS-analysis on the $\mathrm{Si}$ k-edge to check the hypothesis given in [4].

\section{EXPERIMENTAL}

Single-crystalline $\alpha$-SiC ( $6 \mathrm{H}$ polytype) with $4^{\circ}$ off-axis orientation were irradiated at $80 \mathrm{~K}$ with $\mathrm{Na}{ }^{+}$ions of energy $50 \mathrm{keV}$ at fluences of $\Phi=2,3,4,25$ and $100 \cdot 10^{14}$ at $/ \mathrm{cm}^{2}$. The samples were studied using RBS-C with $900 \mathrm{keV}$ $\alpha$ particles to evaluate the amount of disorder and to analyze the damage profile. The irradiation and RBS-C were carried out at the Göttingen ion implanter IONAS [6].

Electron Yield-spectra were taken collecting the drain current of the target for incident beam energies from 1800 $\mathrm{eV}$ to $2400 \mathrm{eV}$ in $1 \mathrm{eV}$ steps on beam-line SA 32 of the $800 \mathrm{MeV}$ positron storage ring SuperACO at LURE using a twocrystal type $\mathrm{InSb}(111)$-monochromator $(0.7 \mathrm{eV}$ resolution). The photons delivered by a bending magnet were focalized using an upstream toroidal mirror of fused silica coated with $150 \mathrm{~nm}$ TiN. All samples were analyzed using standard procedure (linear pre-edge subtraction, third order polynomial atomic absorption, Lengeler-Eisenberger normalization algorithm) and programs [7]. Energy calibration was done using the absorption edge at $1839.1 \mathrm{eV}$ of a pure $\mathrm{Si}$ standard. Data, were then Fourier transformed using a Kaiser window function ( $\mathrm{k}^{2}$ weighting, $\tau=2.5$ ) extending from $k=2.48$ to $11.88 \AA^{-1}$. The back-transformed contribution of the first (C) neighbors $(1.14-1.91 \AA$ ) and second (Si) neighbors $(2.23-3.12 \AA)$ in SiC were fitted using single scattering approach using the experimental amplitude and phase shift functions extracted from the non-irradiated substrate.

\section{RESULTS AND DISCUSSION}

In Fig. 1 we show the damage profiles calculated from the RBS-C spectra. The crystalline-to-amorphous transition in the surface region occurs at a critical fluence of $\Phi=3.5 \cdot 10^{14}$ at $/ \mathrm{cm}^{2}$, while the width of the darnaged region slowly increase for higher fluences. The Fourier transforms of the EXAFS-oscillations in Fig.2 show that the first $C$ neighbor do not change significantly up to $\Phi=4 \cdot 10^{14}$ at $/ \mathrm{cm}^{2}$, while the induced disorder is clearly visible in the decreased amplitude of the second $\mathrm{Si}$ neighbor. That shows, that the $\mathrm{Si}_{-} \mathrm{C}_{4}$ and $\mathrm{C}_{-} \mathrm{Si}_{4}$ tetrahedrons are still present just after 
the crystalline-to-amorphous transition and therefore confirming the interpretation of this state as a random network of those tetrahedrons. For high fluences of $25 \cdot 10^{14}$ at $/ \mathrm{cm}^{2}$ there is a strong reduction of the amplitude of the first $C$ neighbor, while the second Si neighbors of SiC has nearly disappeared. In addition, a new neighbor bond is detected at a distance corresponding to the Si-Si distance in amorphous Si. The radial distribution remains almost the same for further implantation $\left(100 \cdot 10^{14} \mathrm{at} / \mathrm{cm}^{2}\right)$.

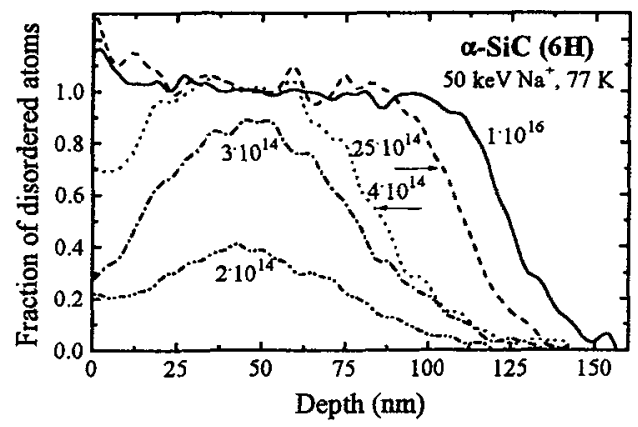

Figure 1: Damage-profiles from RBS-C

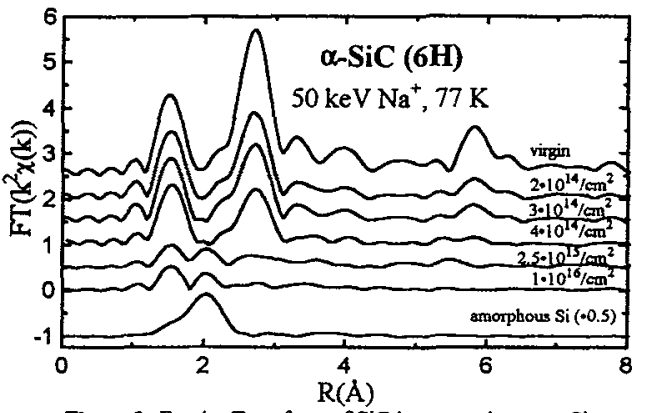

Figure 2: Fourier Transform of $\mathrm{SiC}$ in comparison to a-Si

The results of the quantitative analysis are given in the following table:

\begin{tabular}{|c|ccc|ccc|ccc|}
\hline$\Phi$ & \multicolumn{4}{|c|}{ first neighbor (C) } & \multicolumn{3}{c|}{ second neighbor (Si) } & \multicolumn{3}{c|}{ new bond (Si) } \\
{$\left[10^{14} \mathrm{at}^{-} \mathrm{cm}^{2}\right]$} & $\mathrm{N}$ & $\sigma[\AA]$ & $\mathrm{R}[\AA]$ & $\mathrm{N}$ & $\sigma[\AA]$ & $\mathrm{R}[\AA]$ & $\mathrm{N}$ & $\sigma[\AA]$ & $\mathrm{R}[\AA]$ \\
\hline 0 & 4 & 1.888 & 0.02 & 12 & 3.083 & 0.02 & - & - & - \\
2 & $3.8(3)$ & $1.890(4)$ & $0.049(3)$ & $8.5(3)$ & $3.080(2)$ & $0.049(3)$ & - & - & - \\
3 & $3.6(2)$ & $1.893(2)$ & $0.051(3)$ & $8.4(3)$ & $3.093(2)$ & $0.057(2)$ & - & - & - \\
4 & $3.4(2)$ & $1.896(3)$ & $0.062(5)$ & $7.4(3)$ & $3.099(3)$ & $0.074(4)$ & - & - & - \\
25 & $1.8(4)$ & $1.945(15)$ & $0.108(9)$ & $2.1(3)$ & $3.13(2)$ & $0.09(1)$ & $0.9(2)$ & $2.34(2)$ & $0.09(2)$ \\
100 & $1.5(4)$ & $1.916(15)$ & $0.10(1)$ & $2.0(3)$ & $3.13(2)$ & $0.14(2)$ & $0.8(2)$ & $2.36(2)$ & $0.09(2)$ \\
\hline
\end{tabular}

This values underline the given interpretation on the local environment of the Si-atoms: Nearly no change in the number of C-neighbors up to $\Phi=4 \cdot 10^{14}$ at $/ \mathrm{cm}^{2}$ accompanied by an increase of static disorder. The first neighbor distance increases slightly as a function of the fluence. This is also observed for the second neighbor (Si), of which the number decreases significantly with increasing fluence. For the high fiuence regime, only around 2 next $\mathrm{C}$ neighbors are found. 3 next $\mathrm{Si}$ neighbors are detected, where two thirds are corresponding to the Si-Si distance of the crystalline $\mathrm{SiC}$ and the rest forming direct Si-Si bonds at distances in agreement with amorphous Si. The increase of the distances with increasing damage can be explained by an increase of the number of dangling bonds.

We like to note that the creation of new Si-bonds is also clearly visible in the near edge structure: While the absorption edges of crystalline $\mathrm{Si}$ and crystalline $\mathrm{SiC}$ are separated by $1.2 \mathrm{eV}$, the maximum of the derivative of the edge of the irradiated samples is shifting in direction to the value of Si with increasing fluence [8]. The observed values of next neighbors are in very good agreement with the results of MD simulations [5]. The authors calculate around $2.1 \mathrm{C}$ neighbors at $1.89 \AA$. The simulations predict a first Si neighbor at $2.32 \AA$, followed by a broad maximum around $3 \AA$. As the two peaks overlap, the number of next Si neighbors is not well defined, but also around 2.

In conclusion, we showed via EXAFS analysis, that $\alpha$-SiC amorphized by $\mathrm{Na}^{+}$ion irradiation in the range of $\Phi=2-100 \cdot 10^{14}$ at $/ \mathrm{cm}^{2}$ shows a local order which is in agreement with the interpretation of a random network for low irradiation fluences. For higher fluences around $10^{15}-10^{16}$ at $/ \mathrm{cm}^{2}$, Si-Si bonds are formed, while only 2 next $C$ neighbors are detected and around the same amount of second Si neighbors. The ion-beam amorphized state shows therefore a local Si environment with a chemical order in very good agreement with MD simulations.

\section{Acknowledgments}

One of the authors (M.B.) likes to thank the DFG Sonderforschungsbereich 345 for financial support during his stay in Göttingen.

\section{References}

[1] J.A. Powell, P.G. Neudeck, L.G. Matus and J.B. Petit, Mater. Res. Soc. Symp. Proc., 242 (1992) 495k

[2] See for example: C.J. McHargue and J.M. Williams, Nucl. Instr. and Meth. B80/81 (1993) 889

[3] W.K. Chu, J.W. Mayer and M.A. Nicolet, Backscattering Spectrometry, Academic Press, Orlando, FL, 1978

[4] W. Bolse, J. Conrad, T. Rödle and T. Weber, Surf. Coat. Tech., 74/75 (1995) 927-931

[5] F. Finocchi, G. Galli, M. Parrinello and C. M. Bertoni, Phys. Rev. Let., 68 (1992) 3044-3047

6) M. Uhrmacher, K. Pampus, F.J. Bergmeister, D. Purschke and K.P. Lieb, Nucl. Instr. and Meth. B9 (1985) 234

[7] A. Michalowicz, Logiciels pour la chimie, Ed. Soc. Française de Chimie, Paris, 1991, 102 and A. San-Miguel, Physica B 208 \& 209 (1995), 177

[8] W. Bolse, M. Borowski, J. Conrad, F. Harbsmeier and A. M. Flank, submitted to Phys, Rev. Let. 